\title{
AUMENTO DA TAXA DE RESFRIAMENTO PÓS BOBINAMENTO DE BOBINA LAMINADA A QUENTE PARA OS FLUXOS DE LAMINAÇÃO A FRIO, RECOZIMENTO E ZINCAGEM NA CSN
}

\section{Resumo}

\author{
Leiner Novaes Arêdes ${ }^{1}$ \\ Augusto Cesar Lacerda de Oliveira ${ }^{2}$ \\ Carlaine Fonseca de Souza ${ }^{3}$
}

Após o bobinamento com temperatura controlada, as bobinas são resfriadas até um valor próximo da temperatura ambiente para o processo de decapagem. Há uma bibliografia farta no que diz respeito à temperatura de bobinamento e seus efeitos nas propriedades mecânicas e na microestrutura do aço plano laminado a quente. Contudo, pouco se encontra sobre a influência das taxas de resfriamento pós bobinamento nas propriedades mecânicas e na microestrutura do aço, especialmente nas propriedades finais de materiais que são submetidos à laminação a frio e recozimento. O tempo médio de resfriamento com água é de dois dias. Já o tempo para resfriamento com ar é de sete dias. Estudou-se o efeito das referidas taxas na microestrutura e nas propriedades mecânicas para um determinado aço tanto após a laminação a quente como após a laminação a frio e recozimento.

Palavras-chave: Taxa de resfriamento; Pós bobinamento; Laminação a quente.

\section{HOT ROLLED COIL COOLING RATE INCREASE AFTER COILING FOR COLD ROLLING, ANNEALING AND GALVANIZING IN CSN}

\section{Abstract}

After coiling with controlled temperature, coils are cooled to around the ambient temperature to the pickling process. There is a rich literature regarding the coiling temperature and its effects on mechanical properties and microstructure of hot rolled flat steel. However, there is not much about the influence of cooling rates after coiling in the mechanical properties and microstructure of the steel, especially in the final properties of materials those are cold rolled and annealed. The mean cooling water time is two days. However, the time for forced air cooling is seven days. Were studied the effect of these rates on the microstructure and mechanical properties for a given steel so after hot rolling and after cold rolling and annealing.

Keywords: Cooling rate, After coiling, Hot rolling.

1 Engenheiro Metalúrgico, MSc., Coordenador de Projetos Especiais da CSN, Volta Redonda, Rio de Janeiro, Brasil.

2 Engenheiro Metalúrgico, DSc., Coordenador de Projetos Especiais da CSN, Volta Redonda, Rio de Janeiro, Brasil.

3 Engenheiro Metalúrgico, Gerente de Processos da laminação da CSN, Volta Redonda, Rio de Janeiro, Brasil. 


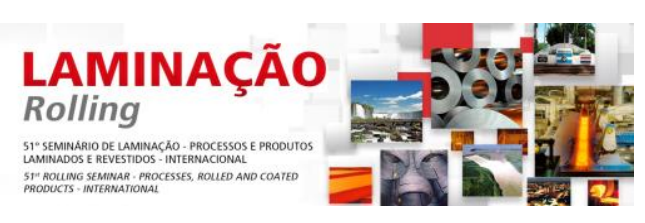

\section{INTRODUÇÃO}

No processo de produção de aços laminados planos, faz-se cada vez mais necessário a otimização de estoques e fluxos.

Após a laminação a quente, o aço precisa aguardar certo tempo para resfriar até próximo da temperatura ambiente para seguir para o processo de decapagem. Com isto, há um estoque alto entre a laminação a quente e a decapagem. Assim, têm-se bobinas prontas, mas que não podem ainda serem decapadas. Por vezes, o cliente final necessita por razão qualquer de antecipações de entrega que não podem ser feitas. Para otimizar os estoques e fluxos, a Companhia Siderúrgica Nacional, CSN, utiliza resfriamento acelerado com água em determinados materiais, de forma a alterar o tempo entre laminação a quente e decapagem de sete para dois dias em média.

\subsection{Fenômenos Envolvidos no Resfriamento da Bobina Laminada a Quente}

Esta aceleração do resfriamento não é feita em determinados materiais para evitar alterações de propriedades mecânicas finais que comprometam a utilização do material.

Diferentes fenômenos metalúrgicos acontecem durante o resfriamento das bobinas laminadas a quente. A resistência mecânica e a dureza de algumas ligas metálicas podem ser adequadas pela formação de precipitados finos uniformemente dispersos de uma segunda fase dentro da matriz da fase original. O mecanismo é chamado endurecimento por precipitação porque as pequenas partículas de uma nova fase são denominadas "precipitados". "Endurecimento por envelhecimento" é também usado para designar este procedimento porque a resistência mecânica se desenvolve com o tempo, ou à medida em que a liga se envelhece [1].

A precipitação de diferentes compostos ocorrem a temperaturas diferentes e em função da composição química do aço. Para o endurecimento por precipitação ocorrer é necessário que a segunda fase seja solúvel em temperaturas elevadas, mas que diminua a sua solubilidade com o decréscimo da temperatura [2]. Os precipitados nos aços planos laminados a quente são formados a partir da solidificação da placa e suas solubilidades são alteradas em temperaturas entre a temperatura de laminação a quente e a temperatura de bobinamento. Contudo, estes precipitados formados, continuam se alterando até que cheguem à temperatura ambiente, pois ainda há difusão de átomos, sobretudo em menor velocidade e em menor quantidade abaixo da temperatura de bobinamento.

Logo, para os materiais que possuem aplicação final na forma de laminado a quente, a aceleração do resfriamento pode interferir nas propriedades mecânicas e na microestrutura do aço devido aos fenômenos que ocorrem após o bobinamento.

Para materiais que seguem o fluxo de laminação a frio e recozimento, a microestrutura original da bobina laminada a quente é completamente alterada nestes processos, pois há o encruamento e a posterior recristalização. Contudo, sabe-se que principalmente para os materiais recozidos em linhas contínuas, os precipitados formados na laminação a quente influenciam na microestrutura e consequentemente nas propriedades mecânicas do material após laminado a frio e recozido. Estes materiais específicos para recozimento contínuo possuem temperatura de bobinamento elevada para que permaneçam mais tempo na faixa de temperatura onde há condições termodinâmicas para que ocorram as precipitações. A formação de precipitados deve ser completa na laminação a quente, pois no

* Contribuição técnica ao $51^{\circ}$ Seminário de Laminação - Processos e Produtos Laminados e Revestidos, 28 a 31 de outubro de 2014, Foz do Iguaçu, PR, Brasil. 


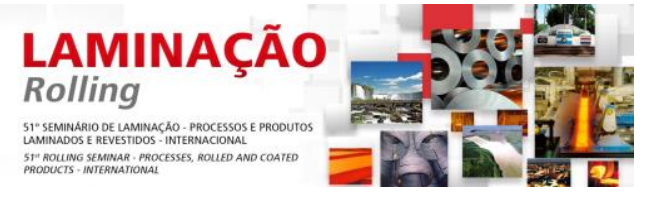

tratamento térmico posterior, o material ao passar pela faixa de temperatura na qual ocorre a formação e coalescimento de cada composto precipitado, não possui condições termodinâmicas adequadas para que haja a precipitação. Assim, a precipitação não ocorre na linha de recozimento contínuo. Uma vez que a precipitação não ocorre, não há o mecanismo de endurecimento por precipitação no processo de recozimento contínuo. Todavia, ocorrerá posteriormente em velocidade muito mais baixa a migração do carbono que não precipitou para as discordâncias, gerando com o tempo o fenômeno conhecido como envelhecimento, o que pode prejudicar a aplicação final do produto. Se a precipitação ocorreu no bobinamento, o envelhecimento após recozimento contínuo será minimizado.

Baseado nos fenômenos acima, preventivamente, para determinados materiais que serão laminados a frio e recozidos, evita-se o resfriamento acelerado com água após laminação a quente no intuito de que as propriedades mecânicas não sejam alteradas. No entanto, pouco se conhece sobre os efeitos práticos do resfriamento acelerado após a laminação a quente nas propriedades mecânicas finais de materiais laminados a frio e recozidos.

A necessidade de antecipação do fornecimento em alguns casos, juntamente com a necessidade de diminuição de estoque intermediário foram as motivações para o estudo de ampliação da gama de materiais laminados a frio e recozidos que pudessem ser resfriados com água após a laminação a quente.

\section{MATERIAIS E MÉTODOS}

Para os corpos de prova para os ensaios de tração foi retirada uma amostra por bobina no sentido longitudinal na base de medida $50 \mathrm{~mm}$. A máquina Instron $5585 \mathrm{H}$, foi utilizada para tração nas amostras laminadas e recozidas, para a determinação das propriedades mecânicas: limite de escoamento, limite de resistência e alongamento.

Após testes em escala laboratorial com aços Intersticial Free, IF, decidiu-se em iniciar os testes em escala industrial. No programa de produção utilizado pela área que faz a estocagem do material laminado a quente na CSN, há um campo que indica se o referido material pode ou não ser resfriado com água, conforme figura 1.

\begin{tabular}{|c|c|c|c|c|c|c|c|c|}
\hline$\Rightarrow \mathrm{CSN}$ & & \multicolumn{3}{|c|}{ Plano de Laminação a Quente } & \multicolumn{3}{|c|}{ Data: $14 / 07 / 2014$} & Página: $1 / 47$ \\
\hline P.Eq. & Caixäo & Item & P. Méd. Pl. & Fluxo & E. Bob. & L. Bob. & Borda & Solda \\
\hline LDC3 & W6668 & H91130 & 19020 & "NN & 2.000 & 830.0 & Com Apara de & NAEO \\
\hline$\overline{\text { Agua no } A B Q}$ & $\mathrm{~N}^{\circ} \mathrm{PI} . \mathrm{CX}$. & \begin{tabular}{l|l} 
P.Fin. & \\
\end{tabular} & \multicolumn{2}{|l|}{ Cliente } & \multicolumn{2}{|l|}{ Uso } & \begin{tabular}{l|l} 
Data Prog. & \\
\end{tabular} & ABQ\#2 \\
\hline Sim & 1 & 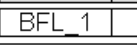 & \multicolumn{2}{|l|}{ NESTLE } & \multicolumn{2}{|c|}{ Tampas - Com Corte Scroll } & $13 / 7 / 2014$ & SIM \\
\hline \multicolumn{9}{|c|}{ Recomendação } \\
\hline \multicolumn{9}{|c|}{ Locação das bobinas no $\mathrm{ABQ}$} \\
\hline
\end{tabular}

Figura 1 - Programa de armazenamento de bobinas laminadas a quente na CSN

O maior volume de produção de materiais que utilizam resfriamento sem água na CSN para as linhas de recozimento e zincagem internas é de materiais comerciais com aplicações finais mais particulares. Entende-se que nestes casos, uma vez que a precipitação ocorra no bobinamento, mesmo que tais precipitados sejam ligeiramente alterados, as aplicações finais não são comprometidas. Optou-se então por estender os testes em escala industrial aos materiais comerciais.

* Contribuição técnica ao $51^{\circ}$ Seminário de Laminação - Processos e Produtos Laminados e Revestidos, 28 a 31 de outubro de 2014, Foz do Iguaçu, PR, Brasil. 


\section{$\underset{\text { Lolling }}{\text { LANIÇÃO }}$

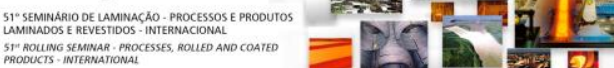

Visto que o volume de materiais não IF que utilizam resfriamento sem água no fluxo de produção de recozimento e zincagem é pequeno, incluiu-se também parte de outros materiais não IF no teste industrial de resfriamento com água.

No acompanhamento do processamento das 3.500 t destes materiais nas linhas de produção posteriores a laminação a quente visou-se entender se havia mudanças nas propriedades mecânicas e consequentemente no comportamento dos materiais em sua aplicação final. Procurou-se também identificar se as condições de processo nos referidos equipamentos não seriam prejudicadas.

\section{RESULTADOS E DISCUSSÃO}

$\mathrm{Na}$ análise do material IF feita em laboratório, foi utilizado microscopia ótica, com ataque Nital 3\%. A microestrutura observada tanto no material resfriado com água quanto no material resfriado ao ar revela microestrutura semelhante, com distribuição de tamanho de grão ferrítico homogênea monomodal com dispersão de precipitados grosseiros, os pontos presentes na microestrutura, conforme figura 2 [4].

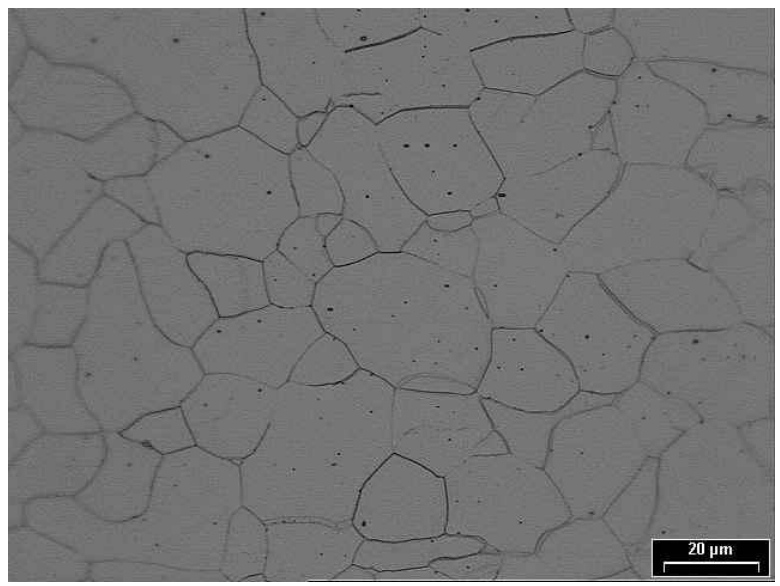

(a)

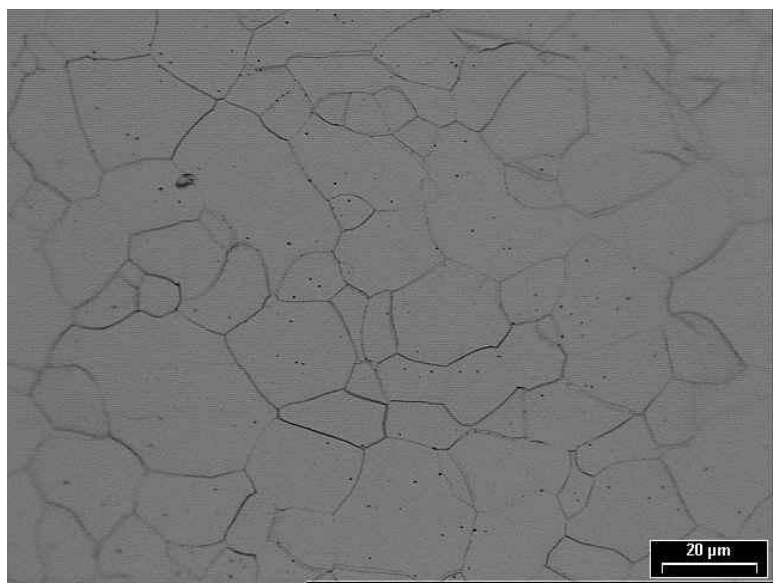

(b)

Figura 2 - Micrografias comparativas da amostra de aço IF laminado a quente com aumento de 500x: (a) com resfriamento normal ao ar (b) com resfriamento acelerado com água até $75^{\circ} \mathrm{C}-$ ataque Klemm's.

Neste tipo de aço laminado a quente, não são encontradas quaisquer variações significativas entre os materiais com resfriamento natural ou acelerado, no que diz respeito a composição, distribuição e tamanho dos precipitados de Ti detectáveis por MEV - TiS e TiN, conforme figuras 3 e 4 [4] - confirmando que estes precipitados se formam a altas temperaturas e são estáveis na faixa de temperaturas abaixo da temperatura de bobinamento.

* Contribuição técnica ao $51^{\circ}$ Seminário de Laminação - Processos e Produtos Laminados e Revestidos, 28 a 31 de outubro de 2014, Foz do Iguaçu, PR, Brasil. 


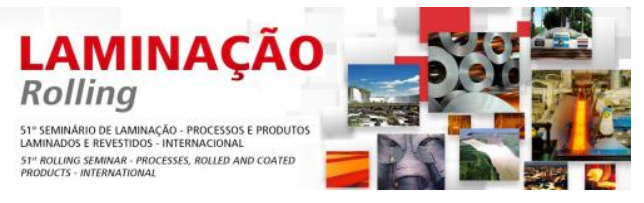

mecânicas dos materiais com resfriamento acelerado após laminação a quente foi encontrada [4].

Para todos os tipos de aço em que foram feitos os testes em escala industrial, não se observa grandes variações de propriedades mecânicas finais em função do resfriamento após laminação a quente acelerado com água. As microestruturas das bobinas laminadas a frio, recozidas e zincadas não apresentaram diferenças significativas, conforme exemplo da figura 5 [4].

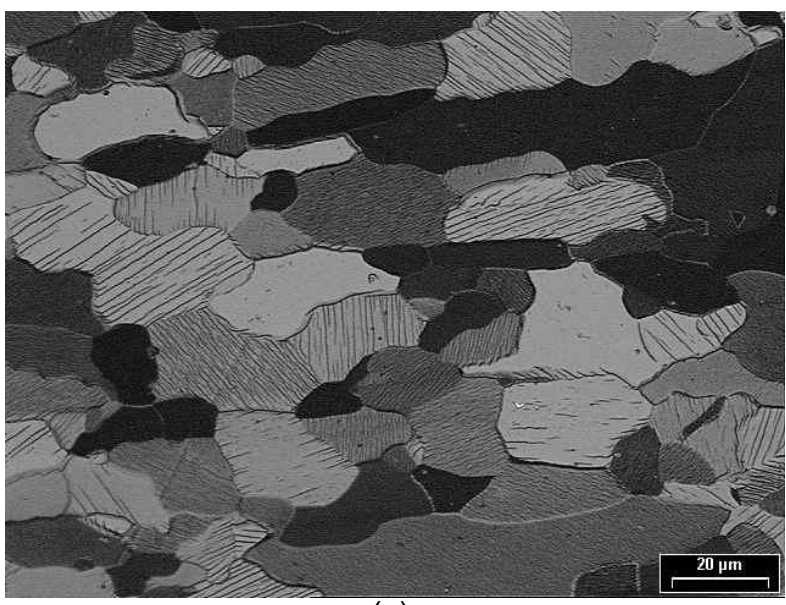

(a)

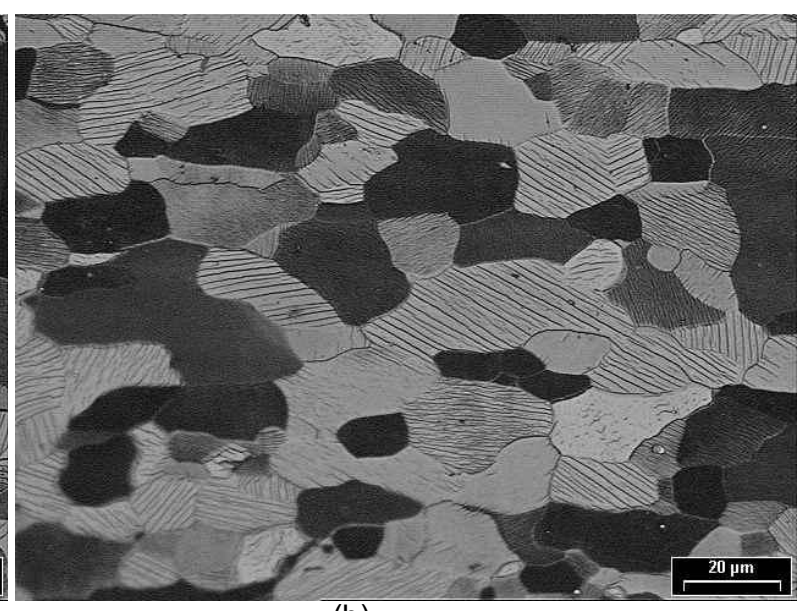

(b)

Figura 5 - Micrografias comparativas da amostra de aço IF laminado a frio e recozido com aumento de 500x: (a) com resfriamento normal ao ar (b) com resfriamento acelerado com água até $75^{\circ} \mathrm{C} \mathrm{-}$ ataque Klemm's.

Para materiais comerciais, cujas especificações não exigem propriedades mecânicas, foi feita a comparação entre a dureza no material resfriado sem água e o material resfriado com água. Os resultados podem ser vistos na figura 6 . Pode-se observar variação de dureza dentro da normalidade de processo deste tipo de aço.

* Contribuição técnica ao $51^{\circ}$ Seminário de Laminação - Processos e Produtos Laminados e Revestidos, 28 a 31 de outubro de 2014, Foz do Iguaçu, PR, Brasil. 


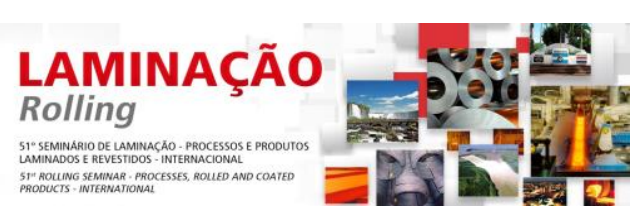

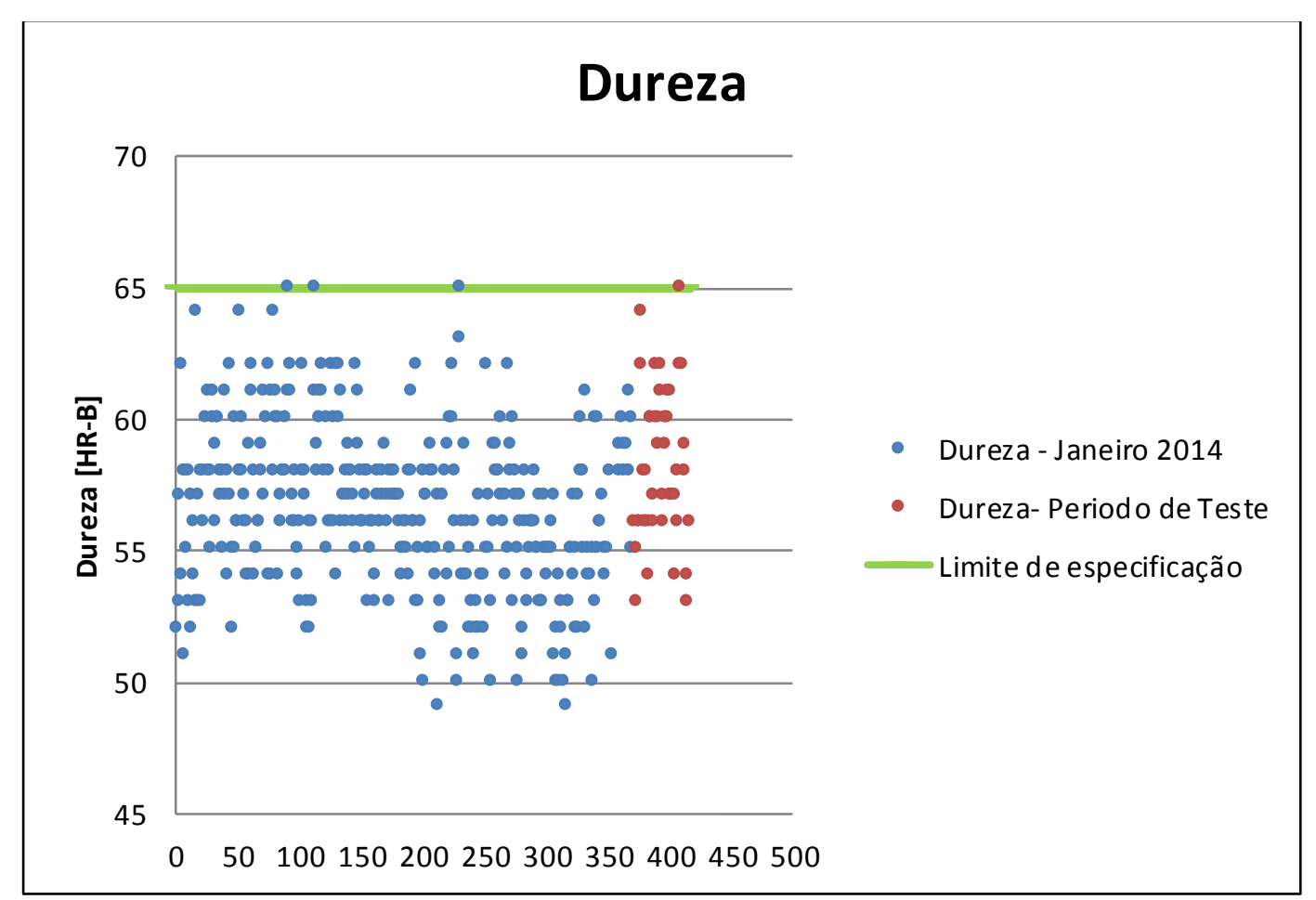

Figura 6 - Comparativo de dureza final em materiais comerciais com resfriamento após bobinamento a quente natural e acelerado na CSN

Para materiais de estampagem, o comparativo entre as propriedades mecânicas destas classes de aço é mostrado nas figuras 7, 8 e 9. Os resultados mostram variações normais de acordo com o processo de produção deste tipo de aço.

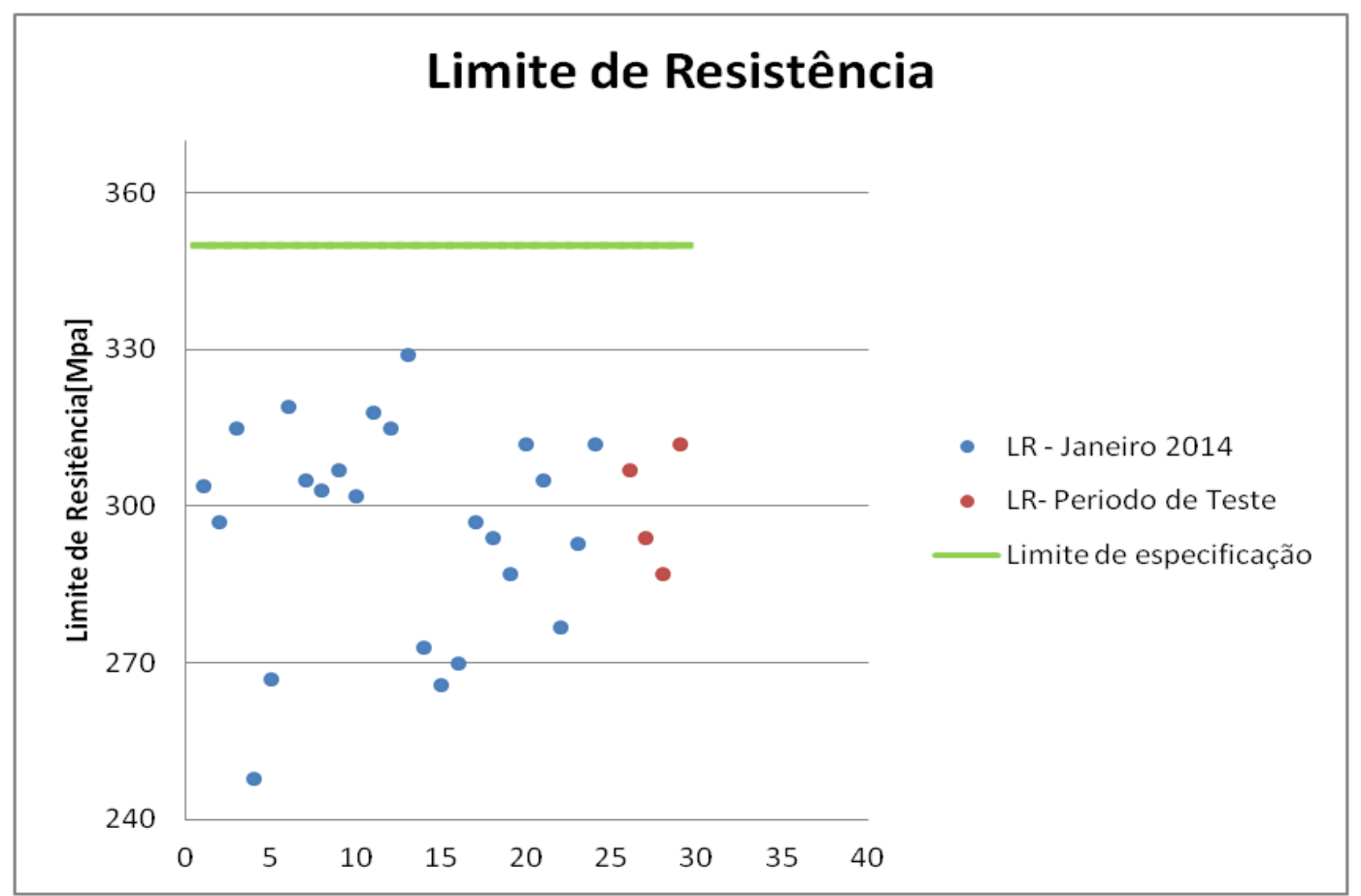

Figura 7 - Comparativo de limite de resistência final em materiais de uma das classes de estampagem com resfriamento após bobinamento a quente natural e acelerado na CSN

* Contribuição técnica ao $51^{\circ}$ Seminário de Laminação - Processos e Produtos Laminados e Revestidos, 28 a 31 de outubro de 2014, Foz do Iguaçu, PR, Brasil. 
LAMINAÇÃO

Rolling

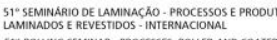

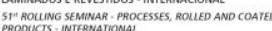

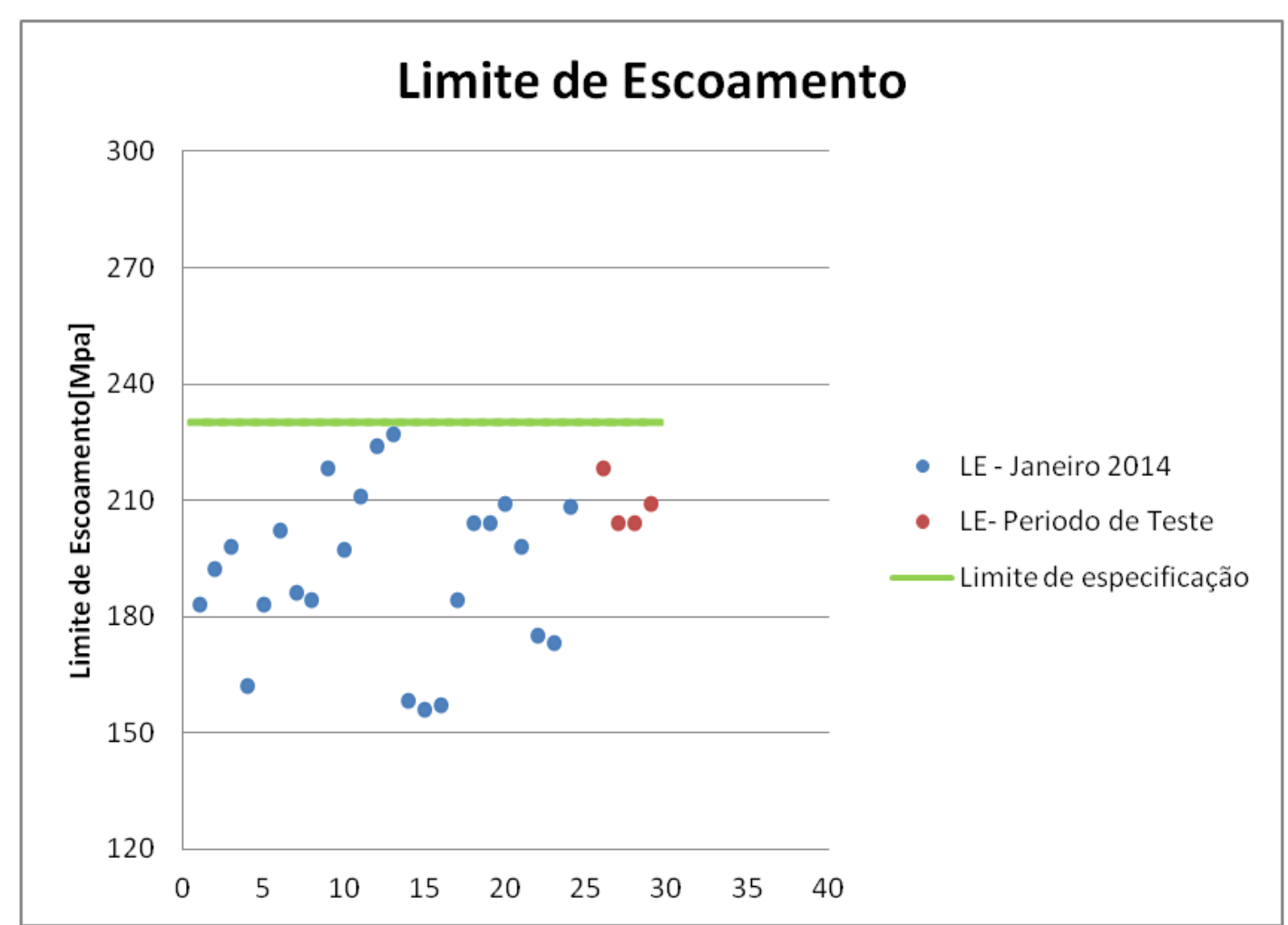

Figura 8 - Comparativo de limite de escoamento final em materiais de uma das classes de estampagem com resfriamento após bobinamento a quente natural e acelerado na CSN

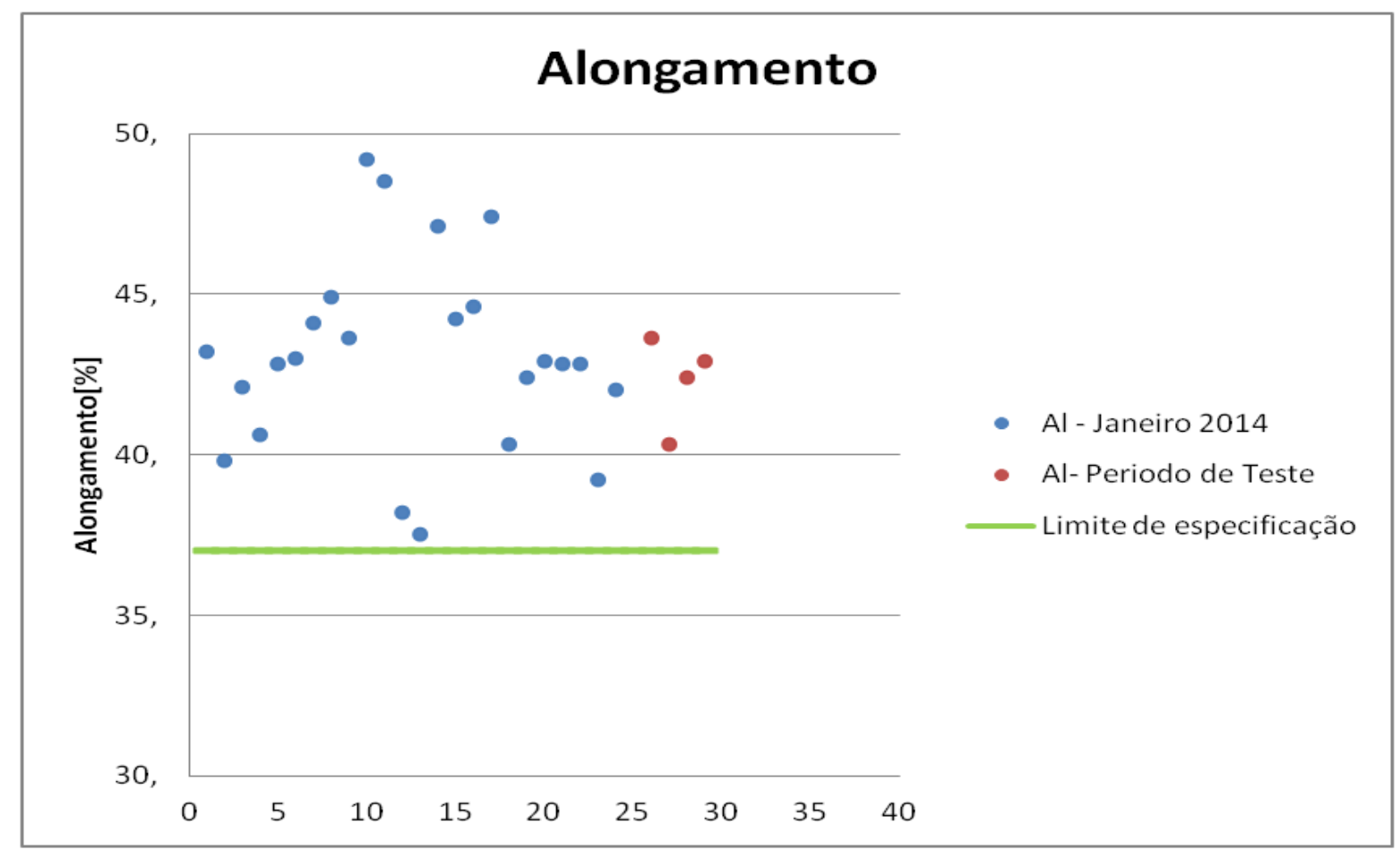

Figura 9 - Comparativo de alongamento final em materiais de uma das classes de estampagem com resfriamento após bobinamento a quente natural e acelerado na CSN

Não foi identificada nenhuma dificuldade operacional no processamento das linhas seguintes. Foi verificada a manutenção dos índices de desvio, de produtividade e rendimento metálico dos materiais testados em relação aos materiais anteriores ao teste.

* Contribuição técnica ao $51^{\circ}$ Seminário de Laminação - Processos e Produtos Laminados e Revestidos, 28 a 31 de outubro de 2014, Foz do Iguaçu, PR, Brasil. 


\section{CONCLUSÃO}

A partir dos resultados obtidos e da análise histórica de propriedades mecânicas, conclui-se que os fenômenos metalúrgicos que ocorrem nos aços laminados planos após o bobinamento a quente não são determinantes das propriedades mecânicas dos materiais laminados a frio, recozidos e zincados por imersão a quente, nem das condições de processamento nas linhas de produção subsequentes a laminação a quente.

A observação é válida especialmente para aços de baixo carbono comum, de qualidade comercial e para aços de estampagem da classe extra low carbon e intersticial free. Para aços de alta resistência até a classe da ordem de $345 \mathrm{Mpa}$ de limite de escoamento, os resultados iniciais mostram também que não há influências significativas da taxa de resfriamento após laminação a quente sobre as propriedades mecânicas. Contudo, especificamente para este tipo de aço, recomenda-se um teste em escala industrial em maior volume de material.

\section{REFERÊNCIAS}

1 Callister WD. Ciência e Engenharia de Materiais Uma Introdução. $5^{\underline{a}}$ ed. Rio de Janeiro: LTC, 2002.

2 Dieter GE. Metalurgia mecânica. 2ed. Rio de Janeiro: Guanabara, 1982

3 Tither G, Garcia Cl, Hua M, Deardo AJ. Precipitation behavior and solute effects in interstitial-free steels, in International Forum for Physsical Metallurgy of IF Steels, Tokyo, 1994.

4 Chaves GM. Análise da influência do resfriamento forçado de BQ'S IF-TI, Trabalho de Conclusão de Curso de Engenharia Metalúrgica, Universidade Federal Fluminense, Rio de Janeiro 2014.

* Contribuição técnica ao $51^{\circ}$ Seminário de Laminação - Processos e Produtos Laminados e Revestidos, 28 a 31 de outubro de 2014, Foz do Iguaçu, PR, Brasil. 